\title{
Knowledge in Wonderland
}

Dr. Philippa (Pip) Mules, SFHEA, LTCL

Senior Lecturer

School of Communication Studies

Faculty of Design \& Creative Technologies

Auckland University of Technology

Office: WG1219, Sir Paul Reeves Building

Phone: +64 99219999 ext, 7853

Email: pip.mules@aut.ac.nz

\section{ABSTRACT}

This article is a media ecology perspective of the epistemological influence of the 'The Wonderland of Knowledge' - a children's encyclopaedia from the early 1940s. It has shown how the highly mechanized production and distribution processes and the highly sedimented material form of this medium mediated perceptions such as: that knowing is an objective, emotionally detached experience; that knowledge is unchanging; that it is possible to know about the world as a certain, unambiguous, decontextualized story and that there is a body of correct knowledge that could be absorbed and considered to be appropriate for everyone. This analysis has also revealed a number of contradictions between the highly sedimented material form of the medium and the more oral elements of its content. In particular, elements of the content are 'close to the human life world', homeostatic and aggregative rather than subordinative.

\section{Keywords}

epistemology, orality, epistemological beliefs, encyclopaedic knowledge, Wonderland of Knowledge, illustrated encyclopaedia, children's encyclopaedia 
Some 75 years have passed since my grandmother purchased The Wonderland of Knowledge children's encyclopaedia from a door-to-door salesman peddling his wares in the rural supply town of Palmerston North in the lower North Island of New Zealand. The encyclopaedia was for my father, aged 12 years at the time. The handsome twelvevolume set, bound in imitation red leather, was published by James Johnston Ltd of Dunedin, Wellington and Auckland, New Zealand, and was bound and printed in Great Britain by Greycaine Ltd, Watford, London. No records remain about how much my grandmother paid for the encyclopaedia, but one can assume that this purchase at this time in history represented a significant financial investment in my father's intellectual development, from which my grandmother would have been seeking some return by way of broadened general knowledge, an enquiring mind and enhanced career prospects.

Although my grandmother thought she was buying my father a tool to broaden his general knowledge and enhance his career prospects, this encyclopaedia had considerable unconscious epistemological influences. Flowing through this knowledge medium were some powerful noetic forces that had a deep, unconscious influence on my father's epistemology and world view. This article explores some of these unconscious influences. First, the article examines the impact of the material processes associated with the printing press on my father's epistemology, and secondly, it examines how, despite claims of the volumes being encyclopaedic in nature, much of their content was more akin to oral ways of knowing.

A central element of a media ecology (Postman 2005) perspective on knowing is that the world is interpreted primarily through sensory rather than intellectual experience (McLuhan 1994; Ong 1977, 2012). Ong (1977) went so far as to attribute differences in 
consciousness between the major phases of communication (oral, text and mass print) to changes in the sensory environment of that period. According to Ong, one of the key features of cultures that communicated using the spoken word is that they were aurally focussed rather than, as in print culture, visually focussed. His particular research emphasis was on how mass printing had fundamentally changed the sensory experience of knowing and had thereby 'restructured consciousness' (Ong 2004, 2012).

McLuhan (1962) also focussed on the profound influence that the medium of print had on the sensory experience of knowing, claiming that print was so perceptually influential that it had 'hypnotized' the Western world.

It is a feature of all social groups that they seek to store and share the knowledge that they perceive to be important within their group and to pass this knowledge on to ensuing generations (Ong 2012; Postman 1998, 2005). The material composition of the medium that is used to convey this knowledge influences perceptions of how the world is imagined to be. This is because sensory engagement with material form, including material elements of the associated production, distribution and consumption cycles of that material form, influences the experience of knowledge.

This is what McLuhan meant when he said that 'the medium is the message' (1969).

Levinson (1997) describes this attribution of material form as a process of sedimentation. At one end of the material scale of knowledge storing and sharing is interpersonal communication that is mediated by the evanescent medium of talk, and at the other end are highly structured, highly sedimented forms of media such as my father's encyclopaedia. According to Ong (2012) Western, twentieth-century perceptions of 
knowledge can be perceived as 'reported talk' that has been attributed physical properties through the material processes of mass printing.

Traditional forms of discourse analysis examine the role that language plays in influencing perception (Gee 1999). This article takes a different approach by looking outside traditional, language-based notions of discourse analysis to examine how perception, particularly epistemological perception, is influenced by material form. It does this by examining how the unique material composition and the associated production, distribution and consumption processes, of The Wonderland of Knowledge are likely to have influenced my father's imaginings about the nature of the world beyond his immediate experience and in particular the value that he placed on some knowledge over other knowledge and what he believed to be true.

Like all forms of media, my father's encyclopaedia had unique material characteristics. It comprised twelve identical, stand-alone, hardcover volumes that measured exactly $19 \mathrm{~cm}$ by $7 \mathrm{~cm}$ by $3.5 \mathrm{~cm}$ and weighed 1.4 kilos. Each set of twelve came with its own dark stained wooden bookcase that was designed to both display the set prominently and function as an item of furniture in its own right as a small surface on which an object such as an ashtray or a handcrafted crocheted doily could be placed.

The red imitation leather binding of each volume was heavily embossed in gold, and with stiff cardboard - approximately $3 \mathrm{~mm}$ thick. They were made to last - today, other than light cracks that expose the netting on the spine, the volumes are in largely the same condition as when my grandmother purchased them some 75 years ago. The fact that they still exist in their original state is testimony to the intensely sedimented nature of their material form (see Figure 1). 


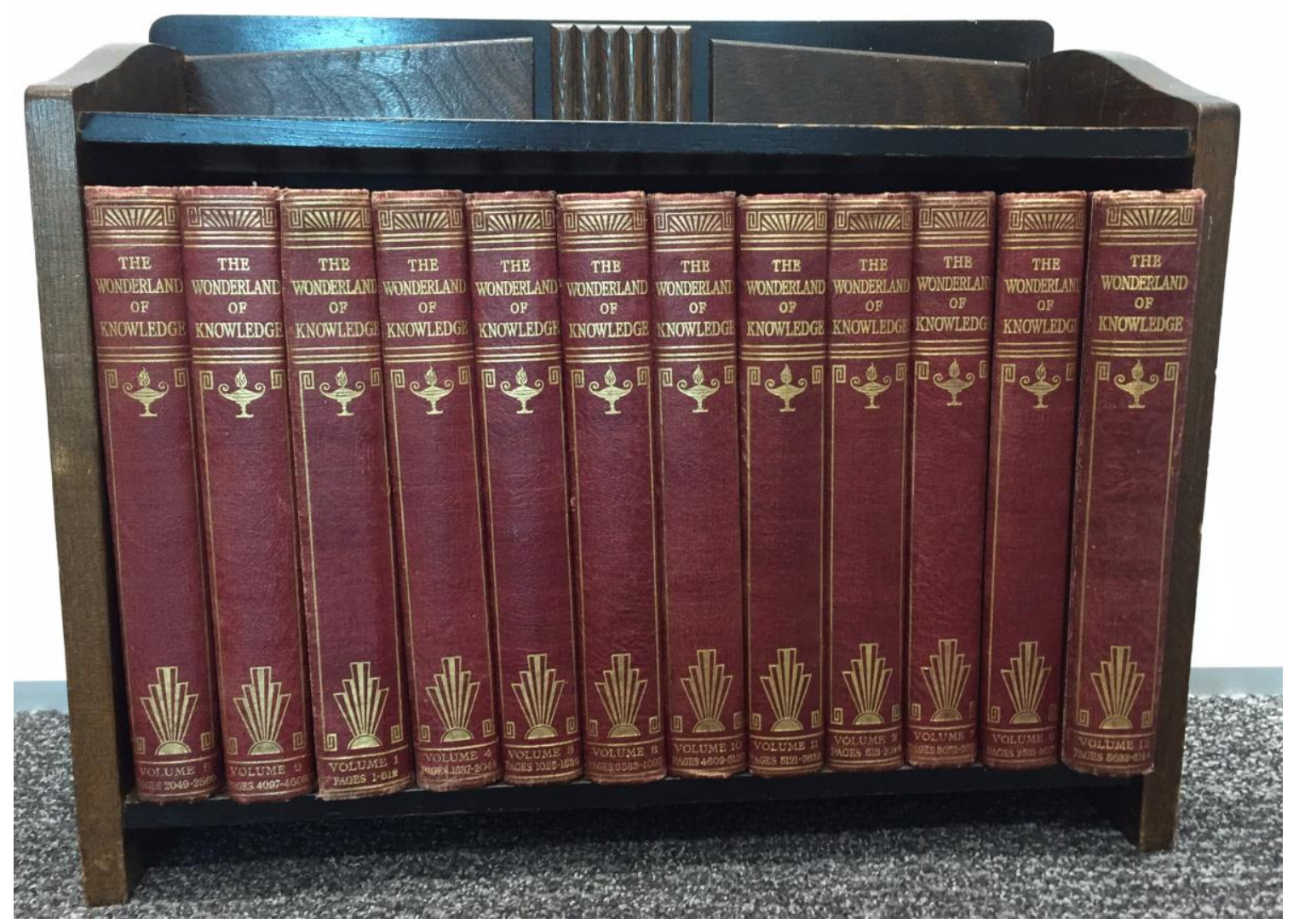

Figure 1: The Wonderland of Knowledge children's encyclopaedia.

My father recalled spending hours poring over this encyclopaedia. It was his primary media centre and, as such, exerted a powerful influence over his sensory experience of knowledge and his perceptions of the wider world. In the late 1930s and early 1940s, the range of knowledge media available in his daily life was very limited. It probably consisted of several hardbound volumes of the classical poets, some 'Boys Own' manuals, perhaps a subscription to Reader's Digest and a few of their abridged books, the family Bible, the daily provincial newspaper, radio broadcasts from the New Zealand Broadcasting Corporation and a bakelite globe of the world. My father did not leave New Zealand for the first time until he was aged 37; this encyclopaedia would have contributed significantly to his perceptions of the world beyond New Zealand up to that first international travel. 
My father recollected being allowed to have only one of the twelve volumes open at a time. He generally lay on his stomach with the book open flat on the floor, his attention moving from column-to-column and row-to-row, or focussed intently on the images. This physically positioned him as an isolated individual engaging visually from a detached viewpoint. McLuhan would have described this knowledge medium as 'hot' and 'single source', with 'high definition' and 'high one-way acceleration' (1994). By this, he meant that the content was presented to my father as a fully developed, immutable whole; my father was not expected to be an active participant in the process of shaping or forming this knowledge. This form of engagement reinforced the perception that it was entirely appropriate for my father to defer to the author and that the content in the encyclopaedia was not to be questioned. When my grandmother saw my father lying on the floor, fully absorbed, she was probably highly satisfied with her investment. From her perspective, this one-sided absorption of content was highly desirable and an indication that my father was on the path to mastering the 'general knowledge' expected of a young man.

Diderot, who is frequently attributed with establishing the concept of encyclopaediae, would have been dismayed to see The Wonderland of Knowledge referred to as an encyclopaedia. The stated aim of the original 'Encyclopédie' was to 'collect and disseminate' knowledge based on human reason instead of nature or theology and 'to set forth its general system to the men with whom we live, and transmit it to those who will come after us' (Encyclopédie, Vol. I, Diderot 1755: 635-48). Although it was marketed as encyclopaedic in format, The Wonderland of Knowledge lacks the conceptual or statistical structuring of content normally associated with encyclopaedic 
knowledge. There is a striking lack of attention to the spatialization and quantification of content normally associated with scientific forms of knowledge. For example, there are virtually no bullet-pointed lists, maps or comparative charts or diagrams. Nor is there any attempt to structure the content into analytic categories. Rather the topics are a random series of stories and historical events organized around an eclectic mix of alluring categories such as 'The Story of the Heavens', 'The Story of the Nations', 'Music through the Ages', 'The Romance of Exploration', 'Great Names in English Literature', ‘Things To Make and Things To Do' and 'Marvels of Invention'. Aeroplanes are described as 'ships that carry cargoes through the paths of the sky' (p. 1927), and ships as 'floating palaces that link continent to continent' (p. 1547). The form of presentation and choice of language are not that of detached scientific neutrality; rather the medium would have positioned my father as a naïve explorer embarking on a voyage of discovery, and the books as a magical door through which the reader enters:

You are now standing at the gateway to the Wonderland of Knowledge. This land - more wonderful than any Fairyland of ancient story - is yours. It is yours for the asking. For here in your hands, you hold the key to the gate - the right of entry to the Wonderland of Knowledge.

(Preface, Vol. I)

Engagement with this knowledge medium would have been an intensely visual experience for my father. In comparison with the other knowledge media that were available in his life at that time, this medium was highly visually alluring.

Promotional material dating from 1937 emphasized the visual nature of The Wonderland of Knowledge. The set was proudly promoted as 'A NEW AND FULLY ILLUSTRATED ENCYCLOPAEDIA' (front endpaper) consisting of 'colour plates, 
numerous black and white in-text photographs, illustrations and engravings' and 'a delightful set, packed with fascinating information on a wide variety of subjects, complete with illustrations, some in colour' (Greycaine Book Manufacturing Company, n.d.). Black and white photographs, diagrams or illustrations appear on almost every page. The volumes' covers are a rich burgundy, and each has grey and white decorated endpapers and four-colour, full-page illustrations. These illustrations depict a range of images derived from historic events, antiquity or fairy tales. For example, the first image in Volume I is a classical depiction of Minerva surrounded by children pointing to the Temple of Wisdom or Knowledge. The first image in Volume II is a highly stylized depiction of the meeting of Hernando Cortes and Montezuma.

The sepia or black and white photographs that are a dominant element of the content of the medium were derived from secondary sources such as photographic libraries, museum catalogues and reproductions of classical art. For example, in Volume II, there are black and white images (most photographs but some drawings) on 366 of the 400 pages. Over half of these images are not attributed to any particular source. Nor are these images referred to or further contextualized in the content; instead, they appear to be included primarily for their visual appeal. This material arrangement of decontextualized images would have contributed to my father's sense that the world outside his own experience was something to be gazed upon in an emotionally detached way. According to McLuhan (1994), one of the sensory attributes of photographs is that they hold the reader's attention as single, static moments in time. 
The people in the images were arranged as though they were catalogued exhibits in a museum. For example, under the rather obtuse section heading 'MAKING RAIN AND MOVING HOUSE', the caption reads,

Water carriers, such as the one in the top left picture, are sometimes seen in parts of the Union. Right, two little darkies from Wankie, in Rhodesia. The Zulu witch-doctor (lower left) is performing a magical dance with the object of making rain. The Matabele woman (lower right) is moving house, complete with family and possessions. (p. 4319)

None of these photographs are attributed to a particular source.

Each volume has a number of four-colour illustrations that are inserted as singlesided leaves. These intensely coloured, highly stylized illustrations are even less related to the textual content than the black and white photographs discussed above; not only is there no reference to the subjects that these images depict elsewhere in the content, but they are bound into the medium at consistent intervals regardless of the content, reflecting their origin as a part of a separate production process. In the late 1930s and early 1940s, the inclusion of these vivid colour plates would have been a significant marketing feature. Rather than contributing to the meaning, they were an affordance of developing printing technology, incorporated to make the medium more visually alluring. This incorporation of 'bling' into the knowledge medium has parallels to Ramist representations of knowledge. Ong (2004) described Ramus as going a little bit 'berserk' with the extreme incorporation of spatial representation into his early textbooks by representing as much content as possible in highly elaborate visual displays. Similarly the publishers of The Wonderland of Knowledge excitedly incorporated the features of colour printing as a means of making the set visually alluring rather than contributing to the meaning. This inclusion of decontextualized images would have contributed to my 
father's sense that coming to know about the world was a process of engaging with visual detachment.

Not only was the sensory experience of engaging with the actual medium epistemologically influential but also the affordances and constraints of the wider production and distribution processes associated with the printing industry influenced my father's epistemology. Activity magazine (as cited by Greycaine Book Manufacturing Company, n.d) noted that in the period between 1935 and 1939, Greycaine Publishing handled an order for six million printed and fully bound large books (500,000 each of twelve volumes). According to Activity, these six million books were almost certainly The Wonderland of Knowledge encyclopaedia. They, like all print-based knowledge media of that time, were produced using the protracted, labour intensive, often hazardous processes associated with the mechanical printing press.

The April 1934 edition of Activity (Greycaine Book Manufacturing Company, n.d) noted that Greycaine Publishing (who produced and shipped this medium to New Zealand) employed a workforce of 1200 people, most of whom were compositors.

Volume III of the Wonderland of Knowledge includes a section showing how the encyclopaedia was produced, with several photographs taken inside the printing works showing a large crew of compositors at work (pp. 1088-89).

The highly mechanical and labour intensive processes associated with the production of this medium had significant epistemological influences.

One of these was the extent to which my father perceived knowledge as being absolute as opposed to subject to change. Schommer (1990, 1993a, 1993b); SchommerAikin (2012) researched personal epistemological beliefs as a heuristic for thinking about 
students' epistemology. According to Schommer and Schommer-Aikin, personal beliefs about knowledge and knowing can be examined along specific dimensions, one of which is the extent to which perceived truths are eternal rather than constantly evolving.

The production and distribution processes associated with The Wonderland of Knowledge directly influenced my father's perception of the extent to which knowledge is stable. The Wonderland of Knowledge encyclopaedia was delivered to Palmerston North, New Zealand, in the early 1940s. Prior to arrival, it would have been in transit in the hold of a ship for many months, after competing for scarce room in the hold of a merchant ship during war time. One of the consequences of this drawn-out production and distribution cycle was that references to time, even unconsciously, are minimized in the encyclopaedia's content. Not only was shipping problematic, but it was technologically difficult and therefore highly uneconomic to update the content regularly. It is noteworthy that although the encyclopaedia was reprinted at least twice between 1900 and 1940, these reprints were a response to demand rather than revisions to the content.

The publishers sought to minimize redundancy of content in order to extend the relevance and therefore marketability of the medium. This was achieved by reducing references to specific dates and time-referenced events. For example, in Volume III, the content includes articles about heroes from the past such as King Arthur; figures from Grecian myths and poets, writers and explorers from the eighteenth and nineteenth centuries.

None of these articles include dates. Likewise, the supposedly scientific article about the solar system (pp. 2681-90) does not contain a single date - thereby presenting 
what is known about the solar system as indisputable. Even time-sensitive topics such as the article about the political situation in Italy leading up to WWII have only seven dates in nine pages. The way that time was represented (or not represented) in this medium reinforced my father's perception that the world was stable and unchanging.

Another of Schommer (1990, 1993a, 1993b) and Schommer-Aikin's (2012) dimensions of personal epistemological beliefs is the extent to which it is perceived as possible to know anything with complete certainty, and whether knowledge consists of highly certain facts as opposed to constantly changing personal constructs. Implicit in the complexities of the production and distribution cycles associated with The Wonderland of Knowledge encyclopaedia was the publisher's need to achieve economies of scale by appealing to a broad international market. To this end, the encyclopaedia reflects conventional thinking of the day and minimization of controversy to ensure it could be sold to as many communities as possible.

Throughout the medium, there is a high level of moralizing and a strong emphasis on preaching the values of Christianity and Empire. For example, the encyclopaedia reinforces the march of colonization and Western civilization - 'More and more countries are being drawn into the magic circle of civilization' (p. 2675).

My father experienced this encyclopaedia during a highly unsettling period of depression and war; however, there is no discussion of the depression and very little discussion about the impending war in the text. This deficiency is very much a production response to the difficulties of updating content using the drawn-out processes associated with the printing industry. Volume XII has a section called 'Important Recent Events'. This section appears to have been inserted at the last minute. It has no page 
numbers, and the specific articles included in this section are not included in the index. It includes an article called 'History in the making - Italy's conquest and annexation of the ancient kingdom of Ethiopia, the martyrdom of Spain and the conflict between the two great yellow races of the far East' (Volume X11, n.pag.). Despite that fact that there is no mention of the political situation in Germany in the title on the final page of this six-page article, there is a ten paragraph account of the rise of Hitler. Unlike almost all of the other content in the encyclopaedia, it is descriptive with no editorializing. This minimization of discussion of contemporary controversy and sociological and political elements of the day contributed to my father's perception that the world was a simple place and facts could be known about it with relative certainty.

There is almost no attempt to cite references or otherwise validate the knowledge claims in the encyclopaedia. While the sources of the images are acknowledged to some extent, at no point in any of the twelve volumes is the text-based content attributed to any one individual. There is acknowledgement that the content is owned from a business perspective - at the beginning of each volume, there is the statement that the content is subject to copyright in all countries subscribing to the Berne Convention. At the time this convention protected all works except photographic and cinematographic work from being copied for at least 50 years after the author's death - for photographic and cinematographic works the period was 25 years. However, there is no sense that the content is the product of any one individual. It can be assumed that the encyclopaedia's content is appropriated almost exclusively from other sources at minimal cost and assembled by an anonymous group of editorial staff. The only individuals specifically mentioned as being involved in the compilation of the content are the publisher James 
Johnston and the editor Ernest Ogan. This lack of attribution would have contributed to the perception that the content was derived from an agreed, 'common sense' pool of legitimate 'general knowledge'. Because the content was presented as independent of any one individual, there was limited opportunity (or need) to challenge the knowledge claims. Insights into the origins of the content or how it evolved through the editorial process were minimized in a way that my father would have seen as entirely appropriate.

Not only was identification of authorship not considered particularly important, but there are also indications that the publishers of this medium did also not consider accuracy of content particularly important. The content was often out of date, poorly researched and not verified and overly simplified. There is no sense that Ogan, his editorial team or any answerable individual had any personal knowledge of the places, events, objects and phenomena that they wrote about. For example:

There was Egypt, a tiny country in Africa, and Sumeria (soo-mě_riä) a smaller land a little way off in Asia. Why do we forget all the rest of the world and begin with these two small areas on the map? The answer is that these were the places where people began reading and writing. (p. 3891)

This may have been the prevailing view of the time but there is no sense that the editorial team considered it necessary to verify this accepted claim, nor is there any concern on the part of the publishers that they may be presenting distorted or incorrect representations of the world.

One repercussion of the technical processes associated with production of this medium was that it was the compositors rather than the editorial team who had the primary influence on the organization of The Wonderland of Knowledge. In other words, the design and layout was to some extent a random by-product of the material 
affordances and constraints of the printing industry rather than a considered attempt to assist my father's learning. Constructivism is at the heart of accepted beliefs about learning (Vygotsky 1962). From this perspective, the cognitive processes associated with arriving at mutually agreed understandings are at the heart of coming to know.

Despite the fact that this encyclopaedia was marketed as a knowledge medium specifically designed for children, the publishers appear to have paid little attention to organizing the content in a way that facilitated the construction of meaningful schema.

For example, the section titled 'Birdlife' (p. 3005) includes an apparently random selection of images of twelve different species of birds. No justification for the particular selection is given. Above the image is a very small explanatory caption stating, 'No matter how odd they look, the beaks on this page are specially suited to the needs of their owners' (p. 3005). However, an analysis of the captions under the image of each bird shows that only three of the twelve are related to the nature of the bird's beaks. Instead most of the captions are amusing anecdotes, such as 'No. 6. The great pied horn-bill, who is not wearing a hat, as one might suppose'; and 'No. 12. This shoe-billed stork seems to be laughing at the African ostrich (No. 11) - or perhaps it is the stork's habitual expression' (p. 3005). This indicates a very casual, rather haphazard approach to aligning the captions, the images and the stated aim of the article. Despite the claims that this is a medium for facilitating knowledge, there is little genuine attention to helping my father organize his thinking about how the shape of a bird's beak is related to its feeding habits. One of the contradictions of this medium is a mismatch between the essentially 'oral' nature of its content and the intensely sedimented, visually uniform design of the medium. Ong (2012) described cultures that used the spoken word as their primary 
medium of storing and sharing knowledge, and who had experienced limited exposure to text, as 'primary oral cultures' (p. 46). He identified a number of features of the nature of knowing in primary oral cultures where the members of that culture have had limited experience of the written word. He observed that, in comparison to literate cultures, knowing in oral cultures was close to the human life world, additive rather than subordinate, evanescent and not permanent, agonistically toned, empathetic and participatory rather than objectively distanced, and homeostatic. The Wonderland of Knowledge pretends to present knowledge in a systematized, objective, encyclopaedic format, yet its content has many of these features of oral ways of knowing.

One of the features of oral ways of knowing $($ Ong 1977, 2012) is that knowing is located in subjective, familiar interactions with human beings and nature, rather than in the objective, analytic categorization associated with text-based ways of knowing.

Ong describes this way of knowing as 'close to the human life world' (2012: 42). Encyclopaedic forms of knowledge are traditionally structured around tree-like, analytic categories - for example, hierarchical branching botanical divisions, or lists of countries, historical periods or political divisions. However, in The Wonderland of Knowledge, engagement with this knowledge medium is not analytic. Instead, the experience is presented as stepping into a glowing, highly sentimentalized and highly editorialized 'wonderland' that is an eclectic parade of stories, comedy and parody.

One example of the way that oral ways of knowing are reflected in the medium is the anthropomorphization of nature. Once again, this is a feature of ways of knowing that are closely embedded in the human life world rather than in the detached analytic categories associated with typographic ways of knowing. The reference above to the bird 
beak captions exemplifies this. Similarly, a moth is described as 'soberly dressed' (p. 173), a butterfly as 'gay, sunshine loving' (p. 116) and a dor beetle as 'solemn' and 'old' and 'slowly plodding along the garden path' (p. 345). Another example of how the human life world has influenced the content is that, rather than being based on analytic, scientific categories, elements of the natural world are described in terms of their influence on daily life. In other words, they are categorized as resources or, as in the example below, in terms of their influence on human resources. For example, the entry about rats states: Rats: Death and destruction follow the trail of the rat. Every year, millions of pounds worth of eggs, meats and small domestic animals such as rabbits and baby chicks are destroyed by this pest. Vicious fighters, they often kill and eat one another and have been known to ATTACK AND KILL pigs, calves and even MEN. White rats bear none of the characteristics of the hated brown rat and are perfectly harmless and may be kept as pets. Dogs, cats, poisons and traps are fairly effective as rat killers, but the best means of control is the construction of rat-proof buildings (p. 5034). Another element of oral ways of knowing that can be detected in The Wonderland of Knowledge is that, although it was designed to be read silently and individually, there was the expectation that the content would be memorized and articulated in some way. This is a residual element of oral ways of knowing. According to Ong (2012), in primary oral societies, knowledge tended to aggregative rather subordinative, with the frequent performance of repetitive poems, songs and chants being an important way of conserving knowledge across generations. My grandmother would have considered it an important element of my father's education as a young gentleman that he was able to remember, articulate and present a repertoire of content. One indication of this residual orality is that 
at the beginning of each volume is a list of simple mnemonic devices such as guides to pronunciation, usage examples and parts of speech for key words. The stated aim of these guides is 'to help readers to pronounce difficult technical words and proper names' ( $\mathrm{p}$. vii), but the implication is that some degree of articulation and display is expected in order to show mastery of the content.

For example, in the section titled 'The WHIRLING FAMILY of the SUN - How His Nine Children Race Round Him Hundreds of Times Faster than an Aeroplane' (p. 2667), pronunciation guides are provided for the words asteroid (ăst-ä-roid) and solar (sōl-ä).

Another example of the incorporation of aggregative devices for remembering content is the depiction of the characters as archetypes that performed heroic and highly memorable deeds. This too is a common mnemonic device used in oral societies (Ong 2012). For example, the article about Florence Nightingale is titled 'The heroine of the Crimea. Florence Nightingale, the Angel of Pity, whose name will shine forever in Letters of Gold in the Pages of English history' (p. 5785). Grace Darling is described as 'The Heroine of Longstone Lighthouse - Undaunted by the Danger of her Selfimposed task, Grace Darling Braved the Storm-swept Sea and brought to Safety Survivors of the Ill-starred Forfarshire' (p. 5734). Even the natural world is ascribed epic status. For example, 'The LORDLY PALM - As useful as It Is Beautiful, the Palm has Long been the Tree of Kings, and one of the Most Valuable Plants in the World' (p. 2641). 


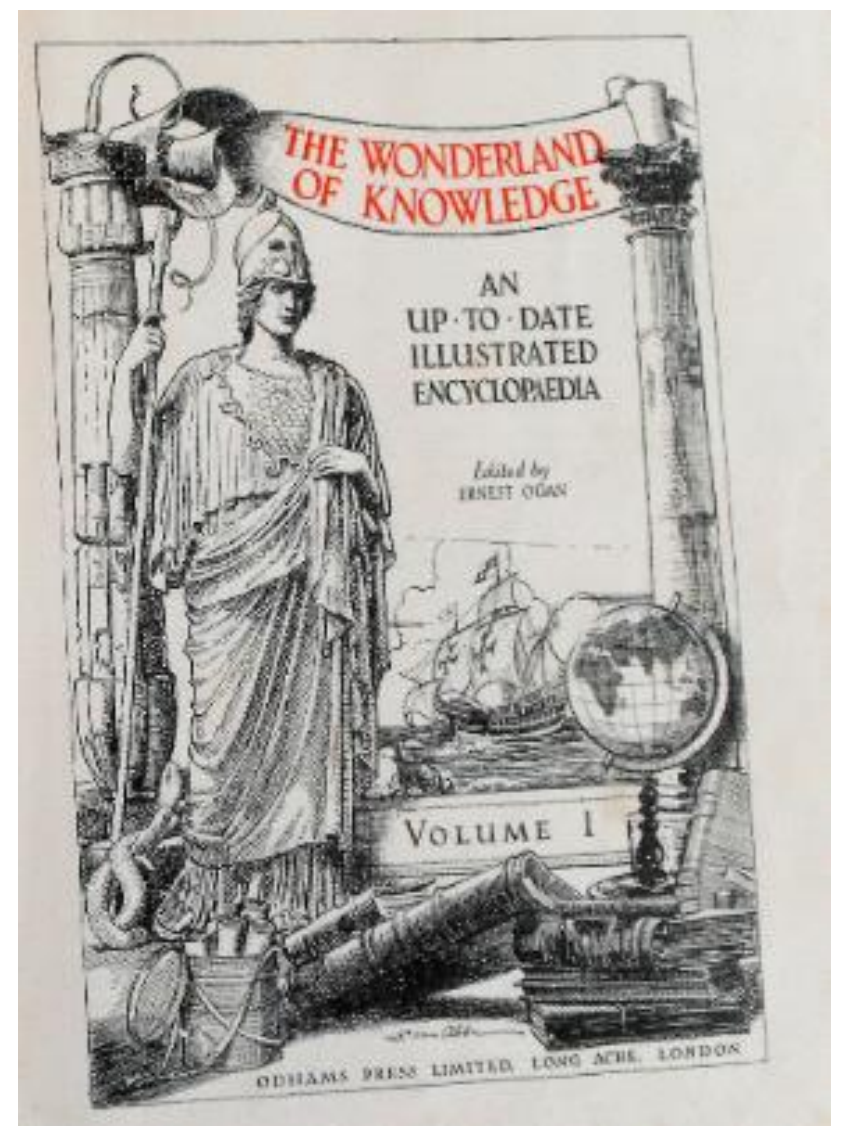

Another feature of knowing in

oral societies is their bias against

novelty and innovation (Goody, 1977;

McLuhan 1962; Ong 1977, 2012).

Ong describes this conservatism as a

tendency towards homeostasis because

primary oral societies rely on memory

as their primary knowledge storage

device.

Figure 3: The frontispiece depicting the Greek Goddess Athena.

Given the limitations inherent in this storage medium, the emphasis on retaining existing knowledge meant that all new knowledge was weighed very carefully before it was embraced. From this perspective, a great deal of emphasis was placed on maintaining a fit between the present and the stories of the past rather than currency of content.

Despite its claims that its content was progressive, much of the content in The

Wonderland of Knowledge was located in the distant past. For example, the 'Famous

Scientists' listed in the index of Volume VI consist of Hippocrates, Galen, William

Harvey, Anthony van Leeuwenhoek, John Hunter, Edward Jenner, Louis Pasteur, Lazaro

Spallanzani, Lord Lister, Euclid and Roger Bacon. These scientists' lives range from as

far back as $400 \mathrm{BC}$ and extend no more recently than the mid-nineteenth century. While 
some of the illustrations are situated in the late nineteenth and early twentieth century (with numerous visual depictions of aeroplanes, steam ships and industry), there are a number of visual contradictions such as the frontispiece of each volume displaying an array of artefacts associated with classical conceptions of knowledge: the Greek god of knowledge Athena posing in front of a set of columns, a large globe and a number of leather bound volumes of books. The idea that valuable knowledge can be located in the distant past is very much a feature of oral societies (Ong 2012).

Today, far from being an exciting treasure trove of knowledge, The Wonderland of Knowledge has become a curious relic from the past - an anachronism, perhaps even an embarrassment. The content is perceived as outdated, faux and kitsch. The once glossy pages are now yellowed, and smell of musty, stale decay. The full set is listed on Amazon.com for amounts ranging from US\$39.99 to US\$449.00. However, no 'bidding wars' are associated with them, and bibliophiles seem to have other preferences.

Whether the volumes of The Wonderland of Knowledge actually ever sell today or whether they just sit unwanted on the sales list is difficult to ascertain given that no sales data are available. Second-hand bookshops specifically do not want them. The New Zealand Salvation Army has posted a sign on their door and on their website specifically requesting that donors do not drop off volumes of old encyclopaedia.

The only value that these once-prized knowledge media have on e-commerce sites, such as E-Bay, is for arts and crafts projects such as making them into lampshades, or drilling a hole through the middle, and holding them in place with a pole to make 'an interesting end table'. 
This article has examined how sensory engagement with the material form of The Wonderland of Knowledge may have subtly influenced my father's unconscious beliefs about the nature of knowledge and his world view. It has shown how the highly mechanized production and distribution processes and the highly sedimented material form of this medium mediated perceptions such as that knowing is an objective, emotionally detached experience; that knowledge is unchanging; that it is possible to know about the world as a certain, unambiguous, decontextualized story and that there is a body of correct knowledge that could be absorbed and considered to be appropriate for everyone.

This analysis has also revealed a number of contradictions between the highly sedimented material form of the medium and the more oral elements of its content. In particular, elements of the content are 'close to the human life world', homeostatic and aggregative rather than subordinative.

\section{REFERENCES}

Diderot, D. (1755), The Encyclopedia of Diderot \& d'Alembert Collaborative

Translation Project (trans. Philip Stewart), Ann Arbor: Michigan Publishing, University of Michigan Library, 2002, http://hdl.handle.net/2027/spo.did2222.0000.004. Accessed 16 January 2016. Trans. of 'Encyclopédie', Encyclopédie ou Dictionnaire raisonné des sciences, des arts et des métiers, vol. 5, Paris.

Gee, J. (1999), An Introduction to Discourse Analysis: Theory and Method, London, England: Routledge.

Please note that this is a separate entry and it goes on a new line. 
Greycaine Book Manufacturing Company,http://www.historypieces.co.uk/Docs/GREYCAINE_BOOK_MANUFACTURING_COMPANY.pd f. Accessed 16 January 2016

Levinson, P. (1997), The Soft Edge: A Natural History and Future of the Information Revolution, New York, NY: Routledge.

McLuhan, M. (1962), The Gutenberg Galaxy: The Making of Typographic Man, London, England: Routledge and Kegan Paul.

— (1969), 'The Playboy Interview', Playboy Magazine, March, 26-@)-63. (1994), Understanding Media: The Extensions of Man, Cambridge, MA:

Massachusetts Institute of Technology Press.

Ogan, E. (ed.) (1933), The Wonderland of Knowledge. A New and Fully Illustrated Encyclopedia, Wellington, New Zealand: James Johnston Limited.

Ong, W. (1977), The Presence of the Word: Some Prolegomena for Cultural and Religious History, New Haven, CT: Yale University Press. ([1958] 2004), Ramus, Method, and the Decay of Dialogue: From the Art of Discourse to the Art of Reason, 3rd ed., Chicago, IL: The University of Chicago Press.

- ([1982] 2012), Orality and Literacy: The Technologizing of the Word, New York, NY: Routledge.

Postman, N. (1998), Five Things We Need To Know About Technological Change, Denver, $\mathrm{CO}$, http://web.cs.ucdavis.edu/ rogaway/classes/188/materials/postman.pdf. 
(2005), Amusing Ourselves to Death: Public Discourse in the Age of Show Business, New York, NY: Penguin.

Schommer, M. (1990), 'Effects of beliefs about the nature of knowledge and comprehension', Journal of Educational Psychology, 82, pp. 498-504.

— (1993a), 'Comparisons of beliefs about the nature of knowledge and learning among postsecondary students', Research in Higher Education, 34, pp. 355-70.

— (1993b), 'Epistemological development and academic performance among secondary students', Journal of Educational Psychology, 85, pp. 406-11.

Schommer-Aikin, M. (2012), 'An evolving theoretical framework for an epistemological belief system', in B.K Hofer and P. R. Pintrich (eds), Personal Epistemology: The Psychology of Beliefs About Knowledge and Knowing, pp. 103-18, Routledge . January 29, 2016.http://www.eblib.com.

Vygotsky, L. (1962), Thought and Language, Cambridge, MA: The Massachusetts Institute of Technology Press. 